$\begin{array}{ll}\text { Research Square } & \text { Preprints are preliminary reports that have not undergone peer review. } \\ \text { They should not be considered conclusive, used to inform clinical practice, } \\ \text { or referenced by the media as validated information. }\end{array}$

\title{
Allergic rhinitis and house dust mite sensitization determine persistence of asthma in children.
}

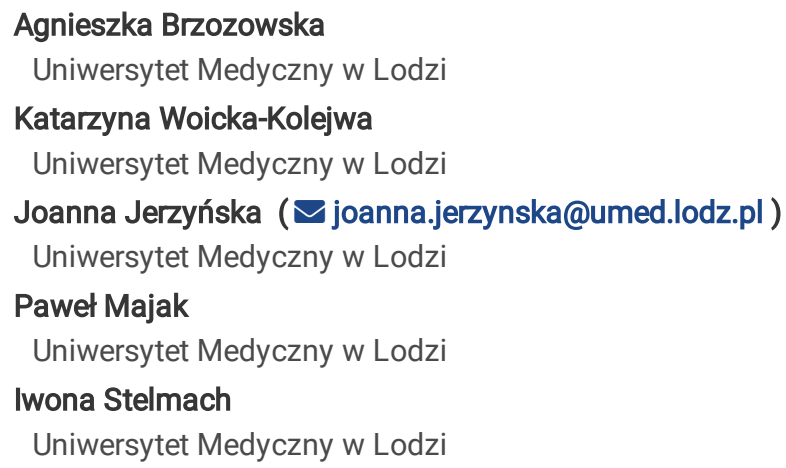

\section{Research}

Keywords: children, asthma persistence, allergic rhinitis, house dust mite sensitization

Posted Date: December 18th, 2020

DOI: https://doi.org/10.21203/rs.3.rs-58863/v2

License: (c) (i) This work is licensed under a Creative Commons Attribution 4.0 International License. Read Full License

Version of Record: A version of this preprint was published at Indian Journal of Pediatrics on March 4th, 2022. See the published version at https://doi.org/10.1007/s12098-021-04052-5. 


\section{Abstract}

Background: MAS study revealed that chronic course of asthma characterized by airway hyper-responsiveness and impairment of lung function at school age is determined by continuing allergic airway inflammation which begin in the first 3 years of life. Respiratory tract infections early in life, childhood allergic comorbidities, exposure to environmental determinants of asthma and active smoking may all contribute to increased risk of allergic disorders. While these correlations have been established, there is little understanding of the immunological mechanisms by which asthma develops into a persistent disease, or by which symptoms regress.

Methods. Eighty patients were included into the analysis. Clinical and immunoregulatory predictors of asthma were analyzed.

Results: Presence of mAPI criteria as well as house dust mite-allergy and allergic rhinitis at 7-10 yeas, were associated with a reduced prevalence of asthma remission. The increased eosinophil blood count in API (Asthma Predictive Index) criteria was associated with a lower expression of CD25 positive cells. Current HDM-allergy was associated with a higher FeNO level and higher expression of CD25CD71 positive cells. Allergic rhinitis was associated with a higher expression of PPAR and CD25CD71 positive cells; in the same group of patients a lower expression of GARP positive cells were observed.

Conclusions: Probability of persistence of childhood asthma was largely determined by the presence of allergic rhinitis and sensitization to HDM. Our results suggest natural remission of clinical symptoms of asthma in children are not fully related to immunoregulation processes. Additionally, API criteria are related to asthma persistence.

\section{Introduction}

Asthma symptoms beginning in adults might have originated in childhood. About $3-5 \%$ of individuals will develop wheeze symptoms that persist from early childhood into adulthood (1). Multicenter Allergy study revealed that the chronic course of asthma characterized by airway hyper-responsiveness and impairment of lung function at school age is determined by continuing allergic airway inflammation which begins in the first 3 years of life. However, children with a non-atopic wheezing phenotype lose their symptoms over school age and retain normal lung function at puberty (2). Respiratory tract infections early in life, childhood allergic comorbidities, exposure to environmental determinants of asthma and active smoking in adolescence and later in life, all may contribute to increased risk of allergic disorders $(1,3)$. While these correlations have been established, there is little understanding of the immunological mechanisms by which asthma develops into a persistent disease, or by which symptoms regress. The mechanisms by which immune responses to antigens lead to either allergy or tolerance involve complex interactions between genetic background and the exposure.

A wide range of cell types and suppressive molecules are involved in induction and maintenance of tolerance. The forkhead transcription factor (Foxp3) expression in regulatory T cells (Tregs) plays a crucial role in maintaining immunological tolerance $(4,5)$. The IL-2 receptor (CD25) and transferrin receptor (CD71) are activation markers of T and B cells, and their increased expression might reflect an increased activation state $(3,6)$. Activation of transcription factors, such as the suppressor of cytokine signaling (SOCS), and peroxisome proliferatoractivated receptor gamma (PPARY), also influence the course of inflammation (PPARy exerts anti-inflammatory effects) $(6,7)$. The expression of suppressor of cytokine signaling 3 (SOCS3) is induced by various cytokines, including IL6, IL10, and interferon (IFN)-gamma $(8,9)$. Glycoprotein A repetitions predominant (GARP) is involved in the regulation of peripheral tolerance (10). Our hypothesis was that some cells' mediators might play more prominent role in these processes than others. Therefore, we assessed the relationship between the expressions of above parameters expression and asthma remission in children.

For further understanding of the natural history of asthma, the current study was designed with the aim to investigate the clinical and immunological parameters which may be associated with the resolution of asthma symptoms. Children with continuous asthma and those in whom childhood asthma symptoms had resolved were compared with respect to a number of criteria including: clinical data, API criteria (Asthma Predictive Index), and immunoregulatory parameters production by peripheral blood mononuclear cells (PBMC).

\section{Patients And Methods}

\section{Patients}

The study was a prospective study based on 80 children, aged $7-10$, who were diagnosed with bronchial asthma $<5$ years of age and remained under the care of our clinic. Patients with concomitant diseases such as congenital or acquired heart and lung diseases, rheumatologic diseases and immunodeficiency were excluded from the study.

At patient's age of 7-10 years parents were requested to attend the clinic with their children by phone call. They were interviewed personally. At the first visit they were informed about the purpose of the study, how to score allergy and asthma symptoms and underwent skin testing. Demographic data regarding sex, type of residence, exposure to molds, animals at home, exposure to tobacco, perinatal history (type of delivery, 
APGAR score, birth weight) as well as family and medical history were taken, patients were classified as atopic based on history and positive skin prick testing. In patients unable to undergo skin testing, a serum specific IgE for a specific allergen was employed. At this visit children were divided into two groups: remission group - children in whom asthma treatment was discontinued by the allergist from our outpatient clinic due to the absence of clinical symptoms of the disease as stated by the family and confirmed with lung function tests and exhaled nitric oxide concentration and the patients' diaries; no ICS, SABA nor LTRAs were allowed (patients with allergic rhinitis were allowed to take nasal steroids), and persistent group - children who remained on anti-asthmatic therapy due to asthma symptoms. One hundred children were screened-until the number of 40 children in each group was reached (total of 80 children). The second visit took place six months after the first one, and the third visit took place 12 months from the first visit. During each visit lung function and exhaled nitric oxide concentration were measured and the patients' diaries were evaluated to confirm asthma status. Additionally, at the third visit, blood samples were obtained from all patients to assess immunological parameters.

\section{Asthma diagnosis in early childhood}

The early childhood asthma ( $<5$ years of age) was diagnosed after at least 1-year of observation by clinician based on asthma symptoms (wheezing, recurrent infections of lower respiratory tract, dyspnea) and using the modified Asthma Predicted Index (mAPI) which requires 4 or more wheezing episodes in the last year, in addition to one of three major criteria: physician-diagnosed parental asthma, physician-diagnosed child eczema, sensitization to $\geq 1$ aeroallergen or two out of three minor criteria: wheezing apart from colds, blood eosinophils $\geq 4 \%$, sensitization to $\geq 1$ food allergen $(11,12)$. Children were followed up in our allergy outpatient clinic.

\section{Asthma remission}

Clinical remission of asthma in our patient was defined as the absence of asthma symptoms for at least 12 months without the use of inhaled corticosteroids and short acting beta2 agonists; the spirometry and reversibility test confirmed complete remission as previously described $(12,13)$

\section{Allergen sensitization}

Skin prick testing to standard allergen extracts was performed using Allergopharma, Reinbek, Germany. Reaction $>3 m m$ in diameter above the negative control recorded at 15 min were considered positive.

The measurements of serum specific IgE was applied, if necessary. Allergen sensitization was defined as specific lgE of $\geq 0.35 \mathrm{KU} / \mathrm{L}$ for at least one of tested allergens (chemiluminescence method (CLIA), Immulite 2000, XPI, Siemens, Germany). For the purpose of the study we defined allergy as the presence of serum IgE of $\geq 0.35 \mathrm{KU} / \mathrm{L}$ specific for allergens: i.e. dust mites, molds, cat and dog dander, grasses, wild grasses, and tree pollen.

\section{Symptom-medication score}

The combined symptom-medication score (SMS) was calculated as a sum of symptom score (SS) and the medication score (MS) recorded by the patients on a daily basis between the visits (14). SS was recorded with the use of a point score system for the most common symptoms of rhinitis (rhinorrhea, sneezing, itching, and nasal congestion), conjunctivitis (ocular pruritus, watery eyes, itching), and respiratory disorders (cough, wheeze, and dyspnea). The results of the score helped to document asthma remission/asthma symptoms as well as allergic rhinitis (AR).

Lung function, body plethysmography (sRtot, Rocc)

All pulmonary function tests were performed with a Master Screen unit (Erich Jaeger Gmbh-Hochberg, Germany), as described elsewhere, in accordance with the ATS/ERS guidelines $(15,16)$. The highest of 3 successful measurements of spirometry was taken and analyzed. The results were expressed as the percentage of a predicted value.

\section{Nitric oxide (NO) measurement}

Fractional exhaled nitric oxide (FeNO) was measured with a chemiluminescence analyser (Sievers NOA 280i, CO, USA). Exhalations were performed in accordance with the ATS/ERS guidelines (17). Children had to maintain a constant expiratory flow of $50 \mathrm{~mL} / \mathrm{s}$ for at least 3 seconds and exhalations were repeated until three measurements were within $5 \%$ of the mean.

Immunological assessment

The following panel of antibodies conjugated with fluorescein isothiocyanate (FITC), phycoerythrin (PE), peridinin-chloro-phyll-protein (Per-CP), or allophycocyanin (APC), was used for the following assays: PPARG-FITC, CD11c-PE, CD 25 FITC, CD 4 PerCP, CD 71 PE, CD 73 , PerCP, AntiGARP APC, FOXP3 PE, (all antibodies from Becton Dickinson, San Diego, CA, USA) and SOCS3 (from Abbexa, Cambridge, UK). All procedures 
were carried out according to the manufacturer's instructions. The detailed description of the immunological tests and cells preparation is included in an appendix.

The study was approved by the Medical Ethics Committee of the Medical University of Lodz. All parents or legal guardians gave their oral and written consent for the evaluation of data from the medical documentation of their children.

\section{Statistical methods}

Statistical analysis was conducted in three steps. The first and second step comprised the logistic regression analysis in univariate followed by the multivariate model. Significant $(p<0.1)$ predictors of asthma remission defined in univariate models were included into the final multivariate model. During the third step, immunological parameters were compared in relation to the presence or absence of previously defined clinical predictors of asthma remission. The significance threshold of p-level was set at 0.05 . The statistical analysis was performed with the STATISTICA 13.1 (StatSoft Poland, Kraków).

\section{Results}

Eighty patients were included into the analysis. Clinical characteristics of study groups are presented in Table 1.

\section{Clinical predictors of asthma remission}

In the first step all available clinical data as independent variables were included into the univariate model of logistic regression analysis together with asthma remission as a dependent variable. We found statistically significant relations in API for sensitization to allergens (OR = $0.29 ; 95 \% \mathrm{Cl}: 0.11$ to $0.76 ; \mathrm{p}<0.0122$ ), with very high significance for allergic rhinitis and rhinoconjuctivitis (respectively- $\mathrm{OR}=0.09 ; 95 \% \mathrm{Cl}: 0.03$ to $0.26 ; \mathrm{p}<0.0001$ and $\mathrm{OR}=0.05 ; 95 \% \mathrm{Cl} ; 0.01$ to $0.38 ; \mathrm{p}<0.0043)$, especially when HDM-allergy was confirmed (OR=0.39;95\%Cl:0.15 to $1.00 ; \mathrm{p}<0.0497)$. We also found significant correlations between asthma remission and blood eosinophils (OR = $0.32 ; 95 \% \mathrm{Cl}$ : 0.12 to 0.84 ; $\mathrm{p}<0.0213)$ and wheezing apart from colds (OR=0.27;95\% $\mathrm{Cl}: 0.08$ to $0.83 ; p<0.0226)$. The results are shown in Table 2 . The presence of $\mathrm{mAPI}$ criteria such as inhalant allergy, wheezing apart from colds, an increased eosinophil blood count, as well as the presence of house dust mite (HDM)-allergy and allergic rhinitis; were associated with decreased probability of asthma remission. Also, a trend towards API parental asthma and parental asthma at present associated with lesser probability of asthma remission ( $p=0.0743$ and $p=0.0876$ respectively) was observed (Table 2). We found statistically significant difference in symptom and medication score between asthmatic children with remission vs persistence $(p<0.0001)$.

\section{Pulmonary function tests}

There was no correlation between asthma remission and lung functions (Table 3 and 4). We found statistically significant correlation between asthma remission and FENO in lower values of FENO: Q2vs Q1(OR=4.77; 95\% Cl: 1.14 to 19.98; $p<0.0327)$ only. The results are given in Table 3 and 4.

\section{Inflammatory/immunoregulatory predictors of asthma remission}

In the second step inflammatory/immunoregulatory data (categorized according to lower and upper quartiles) as independent variables were included into the univariate model of logistic regression analysis together with asthma remission as dependent variable (Table 3 and 4). Only in lower values, the FeNO level was associated with asthma remission as described above (Table 4). The second versus the first quartile of FeNO increased the prevalence of asthma remission, but the third and fourth did not affect it $($ Table 3,4$)$. There was no correlation between asthma remission and immunological parameters (Table 3 and 4).

Finally, all statistical predictors were included into the one model of multivariate logistic regression analysis. The results showed that only the current allergic rhinitis independently decreased the probability of asthma remission ( $\mathrm{OR}=0.15 ; 95 \% \mathrm{Cl}: 0.039$ to 0.56$)$.

\section{Associations between clinical and inflammatory/immunoregulatory predictors of asthma remission}

The presence of increased eosinophil blood count in API (Asthma Predictive Index) criteria was associated with a lower expression of CD25 positive cells but it was not present after correction for multiple comparisons (Table 5). Current HDM-allergy was associated with a higher FeNO level (before and after correction for multiple comparisons) and a higher expression of CD25CD71 positive cells (only before correction for multiple comparisons). Allergic rhinitis was associated with a higher expression of PPAR and CD25CD71 positive cells; in the same group of patients a lower expression of GARP positive cells were observed (all associations were present only before correction for multiple comparisons). 
Allergy to house dust mite allergens and the presence of allergic rhinitis symptoms determine the expression of CD25 + CD $71+$ cells in patients with/without asthma. Figure 1.

\section{Discussion}

There is little understanding of the immunological mechanisms by which asthma develops into a persistent disease, or by which symptoms regress $(18,19)$. A proportion of children with asthma will "outgrow" their disease, and become symptom-free as adults, even though many of them remain hyperresponsive (20-22). Our study was performed to better understand the mechanism why some patients with pre-school asthma show persistent asthma at school age whereas others grow out of this condition. The results provide novel insights into the differences between children whose asthma has resolved spontaneously and those in whom it remains symptomatic. In the presented study only allergic rhinitis was a strong predictor of asthma persistence into adulthood. Hypersensitivity to house dust mite and possibly higher level of exhaled NO (weak association) as well as mAPI criteria, such as sensitization to aeroallergens, blood eosinophils, wheezing apart from colds, were associated with persistent disease. Also, a trend towards parental asthma and allergy associated with lesser probability of asthma remission was observed.

The expression of all immunological parameters between both groups (asthma remission vs asthma persistence) was comparable which suggests that natural remission of clinical symptoms of asthma in children is not related to immunoregulatory processes and only follows the clinical and allergic status. However, immunoregulatory parameters such as CD25, CD25CD71, PPAR, GARP and Foxp3 positive cells are related to the presence of allergic rhinitis, hypersensitivity to dust mites, as well as elevated numbers of eosinophils and wheezing apart from colds in API, which suggest their possible role in the regulation of peripheral tolerance.

In our study, especially the combination of rhinitis and sensitization to HDM predicted the persistence of childhood asthma into school age children. Many studies addressed predictors of remission or persistence of asthma from early childhood through adulthood (23-26). Immunoregulatory parameters related to the outcome of childhood asthma have been widely discussed, however are not yet well established $(4,7,10,19,27)$. Specific observations in the present study, regarding immunology parameters, were surprising. Presence of allergic rhinitis correlated with PPAR, CD25CD71 and GARP. Glycoprotein A repetitions predominant (GARP) has strong anti-inflammatory and regulatory effects on human cells in vitro as well as in vivo. It is involved in the regulation of peripheral tolerance (10) and plays an essential role in mediating suppressive effects of Treg (10 Authors showed that sGARP had a synergistic effect together with Treg by preventing inflammation (10). In our study we showed higher expression of GARP positive cells in patients without AR. Khare et al demonstrated that CD11c-specific PPARy deficiency impairs de novo Foxp3 expression in CD4+ T cells and augments the expression of pro-inflammatory cytokines in CD11c+ cells, therefore impairing airway tolerance induction (28). In the latest study by Chen et al. PPAR-y also as a factor that drives type 2 responses in allergy (7). CD71 increased expression might reflect an increased activation state (6). In our study we revealed a higher expression of PPARY and CD25CD71 in peripheral blood mononuclear cells of patients with allergic rhinitis vs children without AR. Additionally, we found a higher expression of CD25CD71 in children with hypersensitivity to house dust mite. We revealed the association between asthma remission, HDM allergy, the presence of allergic rhinitis and CD25CD71 expression (Figure 1). It is clearly visible that HDM allergy and the presence of allergic rhinitis rather than asthma remission determine CD25CD71 expression. Naturally occurring Tregs, express the FoxP3, which is needed to maintain the suppressive activity of mature peripheral Tregs and is a specific molecular marker of Tregs in human peripheral blood. The Foxp3 expression in Tregs plays a crucial role in maintaining immunological tolerance. In our study, API parameters: wheezing apart from colds correlated with the Foxp3 expression and the blood eosinophils count correlated with higher level of CD25 positive regulatory T cells. The suppressor of cytokine signaling 3 (SOCS3) silencing attenuates eosinophil functions, key inflammatory cells in asthma, however in our study it did not correlate with studied clinical factors.

Our study is the first showing immunological profile of regulatory cells in asthmatic children with asthma persistence or remission. We can hypothesize that the modification of immune regulation in asthmatic children takes place under different interactions.

Our study has some limitations. We have recognized that asthma in childhood is a heterogeneous phenotype, however, our study was not powered to differentiate asthma on phenotype only to characterized factors that contribute to asthma persistence or remission. Also, children with allergic rhinitis and no asthma were allowed to take nasal steroids and this could be enough systemic steroids from nasal steroids to treat especially very mild asthma; they were qualified as remission group. Levels of immunological markers change with age, however only few of them have standard ranges. All immunological measurements were done performed when the children were older therefore all findings are related to the present clinical outcomes. With much larger group of children we could probably find the trend of changes and some correlations of immunological markers and asthma remission/persistence. However this was not an aim of our study. Our study has a limited time of follow up; a longer time of observation would allow us to confirm long-term remission. Also, with bigger sample size differences between parameters could be significant.

Our conclusion is that the probability of persistence of childhood asthma was largely determined by the presence of allergic rhinitis and sensitization to HDM. Our results suggest that natural remission of clinical symptoms for asthma in children are not fully related to

Page 5/11 
immunoregulation processes. Additionally, API criteria such as wheezing apart from colds, elevated blood eosinophils count and sensitization to aeroallergens are related to asthma persistence. The underlying mechanisms for the allergy or tolerance and remission/relapse of asthma symptoms remain unclear, and therefore, future research on asthma should be longitudinal and integrate standardized molecular approaches in identical for both pediatric and adult populations (29).

\section{Abbreviations}

MAS - Multicentre Allergy study

Foxp3 - forkhead transcription factor

Tregs- regulatory $\mathrm{T}$ cells

SOCS- suppressor of cytokine signalling

PPARy-peroxisome proliferator-activated receptor gamma

IFNy - interferon gamma

GARP -Glycoprotein A repetitions predominant

API- Asthma Predictive Index

mAPI - modified Asthma Predictive Index

PBMC - peripheral blood mononuclear cells

FITC - fluorescein isothiocyanate

PE -phycoerythrin

Per-CP- peridinin-chloro-phyll-protein

APC- allophycocyanin

SMS- symptom-medication score

SS- symptom score

MS -medication score

AR- allergic rhinitis

FeNO -Fractional exhaled nitric oxide

NO- nitric oxide

HDM-allergy- house dust mites allergy

OR- odds ratio

\section{References}

1. Amin P, Levin L, Epstein T, et al. Optimum Predictors of Childhood Asthma: Persistent Wheeze or the Asthma Predictive Index? J Allergy Clin Immunol Pract. 2014;2(6):709-715.

2. Illi S, von Mutius E, Lau S, Niggemann B, Grüber C, Wahn U. Multicentre Allergy Study (MAS) group. Perennial allergen sensitisation early in life and chronic asthma in children: a birth cohort study. Lancet. 2006;368(9537):763-770.

3. Stern DA, Morgan WJ, Halonen M, et al. Wheezing and bronchial hyper-responsiveness in early childhood as predictors of newly diagnosed asthma in early adulthood: a longitudinal birth-cohort study. Lancet. 2008;372(9643):1058-1064.

4. Pumputiene I, Emuzyte R, Siaurys A, Tamosiunas V, Valiulis A. CD4+CD25(high) Treg cells in peripheral blood during remission and exacerbation of allergic asthma in children. Acta Paediatr. 2011;100(7):1006-1010. 
5. Matsumoto K, Inoue H, Fukuyama S, et al. Frequency of Foxp3+CD4CD25+ T cells is associated with the phenotypes of allergic asthma. Respirology.2009;14(2):187-194.

6. Ponka P, Lok CN. The transferrin receptor: role in health and disease. Int J Biochem Cell Biol. 1999;31(10):1111-1137.

7. Chen T, Tibbitt CA, Feng X, et al. PPAR-y promotes type 2 immune responses in allergy and nematode infection. Sci Immunol. 2017;2(9).

8. Williams JJ, Munro KM, Palmer TM. Role of Ubiquitylation in Controlling Suppressor of Cytokine Signalling 3 (SOCS3) Function and Expression. Cells. 2014;3(2):546-562.

9. Zafra MP, Cañas JA, Mazzeo C, et al. SOCS3 silencing attenuates eosinophil functions in asthma patients. Int J Mol Sci. 2015;16(3):54345451.

10. Meyer-Martin $\mathrm{H}$, Hahn SA, Beckert $\mathrm{H}$, et al. GARP inhibits allergic airway inflammation in a humanized mouse model. Allergy. 2016;71(9):1274-1283.

11. Chang TS, Lemanske RF Jr, Guilbert TW, et al. Evaluation of the modified asthma predictive index in high-risk preschool children. J Allergy Clin Immunol Pract. 2013;1(2):152-156.

12. From the Global Strategy for Asthma Management and Prevention, Global Initiative for Asthma (GINA) 2014. Available from: http://www.ginasthma.org/.

13. Assar S, Idani E, Monajemzadeh M, et al. Remission of Childhood Asthma after Entering the Second Decade of Life: A Hospital Based Cohort. Ir J Allergy Asthma Immunol. 2013;12(2):124-128.

14. Wasserfallen JB, Gold K, Schulman KA, Baraniuk JN. Development and validation of a rhinoconjunctivitis and asthma symptom score for use as an outcome measure in clinical trials. J Allergy Clin Immunol. 1997;100:16-22.

15. Stelmach I, Sztafiska A, Jerzyska J, Podlecka D, Majak P, Stelmach W. New insights into treatment of children with exercise-induced asthma symptoms. Allergy Asthma Proc. 2016;37(6):466-474.

16. Miller MR, Crapo R, Hankinson J, et al. ATS/ERS Task Force. General considerations for lung function testing. Eur Respir J. 2005;26:153161.

17. Dweik RA, Boggs PB, Erzurum SC, et al. An official ATS clinical practice guideline: interpretation of exhaled nitric oxide levels (FENO) for clinical applications. Recommendations for standardized procedures for the on-line and off-line measurement of exhaled lower respiratory nitric oxide and nasal nitric oxide in adults and children - 2011. This official statement of the American Thoracic Society was adopted by the ATS Board of Directors, 2011. Am J Respir Crit Care Med. 2011; 184(5):602-615.

18. Brewczyński PZ, Brodziak A. Have recent investigations into remission from childhood asthma helped in understanding the pathogenesis of this disease? Med Sci Monit. 2015;21:570-575.

19. van de Veen W, Stanic B, Wirz OF, Jansen K, Globinska A, Akdis M. Role of regulatory B cells in immune tolerance to allergens and beyond. J Allergy Clin Immunol. 2016;138(3):654-665.

20. Savenije OE, Kerkhof M, Koppelman GH, et al. Predicting who will have asthma at school age among preschool children. J Allergy Clin Immunol. 2012;130:325-331.

21. Simpson A, Tan VYF, Winn J et al. Beyond Atopy Multiple Patterns of Sensitization in Relation to Asthma in a Birth Cohort Study. Am J Respir Crit Care Med. 2010;181 (11):1200-1206.

22. Sears MR, Greene JM, Willan AR, et al. A longitudinal, population-based, cohort study of childhood asthma followed to adulthood. New Eng J Med.2003;349(15): 1414-1422.

23. Martin PE, Matheson MC, Gurrin L, et al. Childhood eczema and rhinitis predict atopic but not nonatopic adult asthma: A prospective cohort study over 4 decades. J Allergy Clin Immunol. 2011;127(6):1473-1479.

24. Fu L, Freishtat RJ, Gordish-Dressman H, et al. Natural progression of childhood asthma symptoms and strong influence of sex and puberty. Ann Am Thorac Soc. 2014;11(6):939-944.

25. Roel E, Zetterstrom O, Trell E. Why are some children with early onset of asthma getting better over the years? Diagnostic failure or salutogenetic factors. Int J Med Sci. 2009;6 (6): 348-357.

26. Guerra S, Wright AL, Morgan WJ, et al. Persistence of asthma symptoms during adolescence - Role of obesity and age at the onset of puberty. Am J Respir Crit Care Med.2004;170(1):78-85.

27. Arshad SH, Raza A, Lau L, et al. Pathophysiological characterization of asthma transitions across adolescence. Respir Res. $2014 ; 15: 153$.

28. Khare A, Chakraborty K, Raundhal M, Ray P, Ray A. Cutting Edge: Dual Function of PPARy in CD11c+ Cells Ensures Immune Tolerance in the Airways. J Immunol. 2015;195(2):431-435.

29. Sears MR. Predicting asthma outcomes. J Allergy Clin Immunol. 2015;136(4):829-836.

\section{Tables}

Page $7 / 11$ 
Table 1. Baseline characteristics

\begin{tabular}{|c|c|c|c|c|c|c|c|}
\hline & \multicolumn{2}{|c|}{$\begin{array}{l}\text { Total group } \\
\mathrm{N}=80\end{array}$} & \multicolumn{2}{|c|}{$\begin{array}{c}\text { Asthma } \\
\text { persistence } \\
\mathrm{N}=40\end{array}$} & \multicolumn{2}{|c|}{$\begin{array}{l}\text { Asthma } \\
\text { remission } \\
N=40\end{array}$} & \multirow[t]{2}{*}{$\overline{\mathrm{P}}$} \\
\hline & $\mathrm{N}$ & $\%$ & $\mathrm{~N}$ & $\%$ & $\mathrm{~N}$ & $\%$ & \\
\hline Age [years] at time of diagnosis; mean(SD) & \multicolumn{2}{|c|}{$4.1(2.1)$} & & & & & \\
\hline Age [years] at present; mean SD & \multicolumn{2}{|c|}{$8.2(2.0)$} & \multicolumn{2}{|c|}{$8.4(1.9)$} & \multicolumn{2}{|c|}{$7.9(1.9)$} & 0.1871 \\
\hline male gender, $\mathrm{N}(\%)$ & & 53.8 & & & 22 & 55 & 0.8225 \\
\hline BMI $[\mathrm{kg} / \mathrm{m} 2]$; mean(SD) & \multicolumn{2}{|c|}{$18.4(3.9)$} & \multicolumn{2}{|c|}{$18.8(4.5)$} & \multicolumn{2}{|c|}{$17.9(3.1)$} & 0.5819 \\
\hline early life data & & & & & & & \\
\hline pre-term delivery, $\mathrm{N}(\%)$ & 8 & 10 & 6 & 15 & 2 & 5 & 0.1281 \\
\hline cesarean delivery, $\mathrm{N}(\%)$ & 31 & 38.75 & 15 & 37 & 16 & 40 & 0.8185 \\
\hline APGAR [points]; median(quartile range) & \multirow{2}{*}{\multicolumn{2}{|c|}{$\begin{array}{c}10(9 \text { to } 10) \\
3225(2910 \text { to } 3600)\end{array}$}} & \multirow{2}{*}{\multicolumn{2}{|c|}{$\begin{array}{c}9,5(9 \text { to } 10) \\
3225(2920 \text { to } 3600)\end{array}$}} & \multirow{2}{*}{\multicolumn{2}{|c|}{$\begin{array}{c}10(9 \text { to } 10) \\
3240(2880 \text { to } 3600)\end{array}$}} & 0.4182 \\
\hline birth weight [g]; median(quartile range) & & & & & & & 0.9985 \\
\hline $\begin{array}{l}\text { API index, } \mathbf{N}(\%) \\
\text { API atopic dermatitis }\end{array}$ & 53 & 663 & 27 & 67 & 26 & 65 & 08131 \\
\hline API sensitization to allergens & 51 & 63.8 & 31 & 77 & 20 & 50 & 0.0098 \\
\hline API parental asthma & 36 & 45.0 & 22 & 55 & 14 & 35 & 0.0712 \\
\hline API eosinophils & 28 & 35.0 & 19 & 47 & 9 & 22 & 0.0181 \\
\hline API wheezing & 61 & 76.3 & 35 & 87 & 26 & 65 & 0.0163 \\
\hline API food allergy & 41 & 51.3 & 20 & 50 & 21 & 52 & 0.8230 \\
\hline \multicolumn{8}{|l|}{ environment, $\mathrm{N}(\%) *$} \\
\hline ETS & 20 & 25.0 & 9 & 22 & 11 & 27 & 0.4710 \\
\hline animals at home & 48 & 60.0 & 27 & 67 & 21 & 52 & 0.1699 \\
\hline \multirow{2}{*}{\multicolumn{6}{|c|}{ allergy profile, $\mathrm{N}(\%) *$}} & 5 & 1.0 \\
\hline $\begin{array}{l}\text { allergy protile, } \mathbf{N}(\%)^{*} \\
\text { cat }\end{array}$ & & 24.1 & & 25 & & & 08415 \\
\hline dog & 4 & $\begin{array}{c}24.1 \\
5.1\end{array}$ & 1 & 2.5 & 3 & $\begin{array}{l}2.2 \\
7.5\end{array}$ & 0.2827 \\
\hline HDM & 31 & 39.2 & 20 & 50 & 11 & 27 & 0.0461 \\
\hline molds & 10 & 12.7 & 7 & 17 & 3 & 7.5 & 0.1842 \\
\hline grass & 30 & 38.0 & 19 & 47 & 11 & 27 & 0.0759 \\
\hline tree & 18 & 22.8 & 9 & 22 & 9 & 22 & 0.9513 \\
\hline food & 17 & 21.5 & 10 & 25 & 7 & 17 & 0.4447 \\
\hline positive family history, $\mathrm{N}(\%) *$ & 34 & 43.0 & 21 & 52 & 13 & 32 & 0.0843 \\
\hline Mothers' allergy & 19 & 24.1 & 11 & 27 & 8 & 20 & 0.4667 \\
\hline Father' allergy & 16 & 20.3 & 11 & 27 & 5 & 12 & 0.1009 \\
\hline \multicolumn{8}{|l|}{ co morbidities, $\mathrm{N}(\%) *$} \\
\hline Atopic dermatitis & 17 & 21.3 & 10 & 25 & 7 & 17 & 0.4113 \\
\hline Allergic rhinitis & 45 & 56.3 & 33 & 82 & 12 & 30 & $<0.0001$ \\
\hline Allergic rhinoconjuctivitis & 15 & 18.8 & 14 & 35 & 1 & 2.5 & $<0.0001$ \\
\hline
\end{tabular}

*At present

Table 2. Associations between asthma remission, defined as dependent variable and group of independent variable in univariate model of logistic regression analysis

\begin{tabular}{|c|c|c|c|c|}
\hline Independent variable & $\mathrm{OR}^{\mathrm{a}}$ & \multicolumn{2}{|c|}{$95 \%$ CI } & $\bar{P}$ \\
\hline Age (continues variable) & 0.88 & 0.70 & 1.10 & 0.2589 \\
\hline Male gender & 1.11 & 0.46 & 2.66 & 0.8226 \\
\hline API atopic dermatitis & 0.89 & 0.35 & 2.26 & 0.8131 \\
\hline API sensitization to allergens & 0.29 & 0.11 & 0.76 & 0.0122 \\
\hline API parental asthma & 0.44 & 0.18 & 1.08 & 0.0743 \\
\hline API eosinophils & 0.32 & 0.12 & 0.84 & 0.0213 \\
\hline API wheezing & 0.27 & 0.08 & 0.83 & 0.0226 \\
\hline API Food Allergy & 1.11 & 0.46 & 2.66 & 0.8230 \\
\hline weight & 1.00 & 1.00 & 1.00 & 0.8441 \\
\hline APGAR & 1.33 & 0.85 & 2.09 & 0.2151 \\
\hline ETS & 1.19 & 0.42 & 3.34 & 0.7441 \\
\hline BMIA & 0.94 & 0.83 & 1.05 & 0.2718 \\
\hline IgE total & 1.00 & 1.00 & 1.00 & 0.2117 \\
\hline Cat* & 0.90 & 0.32 & 2.53 & 0.8416 \\
\hline dog* & 3.25 & 0.32 & 32.68 & 0.3169 \\
\hline HDM* & 0.39 & 0.15 & 1.00 & 0.0497 \\
\hline molds* & 0.39 & 0.09 & 1.65 & 0.2012 \\
\hline grass* & 0.43 & 0.17 & 1.10 & 0.0799 \\
\hline tree* & 1.03 & 0.36 & 2.96 & 0.9513 \\
\hline food* & 0.66 & 0.22 & 1.95 & 0.4475 \\
\hline Parental asthma & 0.45 & 0.18 & 1.12 & 0.0876 \\
\hline Atopic dermatitis & 0.64 & 0.22 & 1.88 & 0.4143 \\
\hline Allergic rhinitis & 0.09 & 0.03 & 0.26 & 0.0001 \\
\hline Allergic rhinoconjuctivitis & 0.05 & 0.01 & 0.38 & 0.0043 \\
\hline Animals at home & 0.53 & 0.21 & 1.32 & 0.1729 \\
\hline Molds at home & 1.00 & 0.13 & 7.47 & 1.0000 \\
\hline
\end{tabular}


a dependent variable: asthma remission vs persistence asthma

* sensitization to allergens measured during a year of observation

Table 3. Pulmonary function tests and laboratory results by study groups. Data are presented by median value with lower (Q25) and upper (Q75) quartiles.

\begin{tabular}{l|c|c|c|c|c|c|c|c|c|}
\hline & \multicolumn{4}{c}{ Asthma persistence } & \multicolumn{3}{c}{ Asthma remission } & P \\
\hline & N & median & Q25 & Q75 & N & median & Q25 & Q75 & P \\
\hline EV1[\% pred] & 37 & 101 & 90 & 114 & 35 & 106 & 100 & 118 & 0.1100 \\
\hline EV1FVC [\% pred.] & 38 & 102 & 95 & 109 & 35 & 102 & 96 & 108 & 0.9344 \\
\hline tot [\% pred.] & 35 & 185 & 152 & 225 & 31 & 202 & 151 & 228 & 0.3641 \\
\hline occ [\% pred.] & 37 & 167 & 140 & 195 & 33 & 159 & 146 & 203 & 0.7701 \\
\hline eNO [ppb] & 38 & 22 & 13 & 29 & 33 & 18 & 15 & 26 & 0.9043 \\
\hline PAR [\%] & 40 & 21.2 & 11.3 & 25.8 & 40 & 13.2 & 5.2 & 20.4 & 0.0584 \\
\hline D25 [\%] & 40 & 1.2 & 0.9 & 1.6 & 40 & 1.2 & 0.9 & 1.5 & 0.9580 \\
\hline oxp3 [\%] & 40 & 25.6 & 10.8 & 53.1 & 40 & 27.3 & 15.9 & 62.6 & 0.6842 \\
\hline OCS3 [\%] & 40 & 49.9 & 24.6 & 76.9 & 40 & 51.9 & 32.0 & 76.4 & 0.6983 \\
\hline D25CD71 [\%] & 40 & 2.2 & 1.3 & 4.7 & 40 & 2.2 & 1.4 & 4.6 & 0.7704 \\
\hline APR [\%] & 40 & 14.2 & 9.0 & 23.2 & 40 & 14.6 & 7.8 & 22.2 & 0.7558 \\
\hline
\end{tabular}

Table 4 Associations between asthma remission, defined as dependent variable and group of independent variable in univariate model of logistic regression analysis

\begin{tabular}{|c|c|c|c|c|c|}
\hline & & $\mathrm{OR}^{\mathrm{a}}$ & & \%CI & $\mathrm{P}$ \\
\hline FEV1 [\% best] & Q2 vs Q1 & 3.30 & 0.83 & 13.18 & 0.0911 \\
\hline & Q3 vs Q1 & 1.54 & 0.37 & 6.45 & 0.5545 \\
\hline & Q4 vs Q1 & 3.03 & 0.75 & 12.21 & 0.1200 \\
\hline FEV1/FVC [\% best] & Q2 vs Q1 & 1.25 & 0.31 & 5,07 & 0.7549 \\
\hline & Q3 vs Q1 & 2.06 & 0.57 & 7.47 & 0.2698 \\
\hline & Q4 vs Q1 & 1.04 & 0.28 & 3.92 & 0.9550 \\
\hline Rtot [\% best] & Q2 vs Q1 & 0.45 & 0.11 & 1.92 & 0.2837 \\
\hline & Q3 vs Q1 & 1.13 & 0.29 & 4,41 & 0.8658 \\
\hline & Q4 vs Q1 & 1.13 & 0.29 & 4.41 & 0.8658 \\
\hline Rocc [\% best] & Q2 vs Q1 & 2.86 & 0.72 & 11.31 & 0.1348 \\
\hline & Q3 vs Q1 & 0.44 & 0.10 & 1.93 & 0.2762 \\
\hline & Q4 vs Q1 & 1.79 & 0.47 & 6.82 & 0.3966 \\
\hline FeNO [ppb] & Q2 vs Q1 & 4.77 & 1.14 & 19.98 & 0.0327 \\
\hline & Q3 vs Q1 & 0.92 & 0.23 & 3.70 & 0.9028 \\
\hline & Q4 vs Q1 & 1.47 & 0.38 & 5.72 & 0.5814 \\
\hline PPAR [\%] & Q2 vs Q1 & 1.00 & 0.28 & 3.54 & 1.0000 \\
\hline & Q3 vs Q1 & 0.55 & 0.16 & 1.91 & 0.3440 \\
\hline & Q4 vs Q1 & 0.36 & 0.10 & 1.29 & 0.1174 \\
\hline CD25 [\%] & Q2 vs Q1 & 1.36 & 0.39 & 4.79 & 0.6340 \\
\hline & Q3 vs Q1 & 1.22 & 0.35 & 4.24 & 0.7516 \\
\hline & Q4 vs Q1 & 0.91 & 0.26 & 3.20 & 0.8821 \\
\hline Foxp3 [\%] & Q2 vs Q1 & 1.22 & 0.35 & 4.24 & 0.7516 \\
\hline & Q3 vs Q1 & 1.00 & 0.29 & 3.48 & 1.0000 \\
\hline & Q4 vs Q1 & 1.83 & 0.52 & 6.43 & 0.3440 \\
\hline SOCS3 [\%] & Q2 vs Q1 & 1.10 & 0.31 & 3.88 & 0.8821 \\
\hline & Q3 vs Q1 & 1.63 & 0.47 & 5.60 & 0.4380 \\
\hline & Q4 vs Q1 & 1.22 & 0.35 & 4.24 & 0.7516 \\
\hline CD25CD71 [\%] & Q2 vs Q1 & 0.74 & 0.21 & 2.64 & 0.6431 \\
\hline & Q3 vs Q1 & 0.98 & 0.27 & 3.52 & 0.9726 \\
\hline & Q4 vs Q1 & 0.89 & 0.24 & 3.24 & 0.8584 \\
\hline GAPR [\%] & Q2 vs Q1 & 0.60 & 0.17 & 2.11 & 0.4220 \\
\hline & Q3 vs Q1 & 0.90 & 0.26 & 3.07 & 0.8665 \\
\hline & Q4 vs Q1 & 0.82 & 0.24 & 2.84 & 0.7516 \\
\hline
\end{tabular}

a dependent variable: asthma remission vs persistence asthma

Q1-Q4: quartile 1- 4 
Table 5. Comparisons of inflammatory parameters between presence and absence of clinical predictors of asthma remission. Data are presented as: Mmedian value, Q25 - lower quartile, Q75 - upper quartile and compared with Mann-Whitney test. P-adjusted according to Benjamini and Hochberg correction for multiple comparisons.

\begin{tabular}{|c|c|c|c|c|c|c|c|c|c|c|c|c|c|c|c|c|c|c|c|c|c|}
\hline & \multicolumn{3}{|c|}{ FeNO [ppb] } & \multicolumn{3}{|c|}{ PPAR [\%] } & \multicolumn{3}{|c|}{ CD25[\%] } & \multicolumn{3}{|c|}{ Foxp3[\%] } & \multicolumn{3}{|c|}{ SOCS3[\%] } & \multicolumn{3}{|c|}{ CD25CD71[\%] } & \multicolumn{3}{|c|}{ GAPR[\%] } \\
\hline & $Q 25$ & $M$ & $Q 75$ & $Q 25$ & $M$ & $Q 75$ & $Q 25$ & $M$ & $Q 75$ & $Q 25$ & $M$ & $Q 75$ & $Q 25$ & $M$ & $Q 75$ & $Q 25$ & $M$ & Q75 & $Q 25$ & $M$ & Q75 \\
\hline $\begin{array}{l}\text { API } \\
\text { (allergy) }\end{array}$ & & & & & & & & & & & & & & & & & & & & & \\
\hline absence & 13.8 & 17.9 & 21.8 & 5.6 & 13.3 & 25.2 & 0.7 & 1.1 & 1.5 & 16.5 & 40.0 & 62.6 & 36.6 & 56.5 & 73.4 & 1.1 & 1.7 & 3.2 & 7.7 & 12.8 & 18.7 \\
\hline presence & 15.1 & 21.7 & 29.2 & 7.4 & 16.2 & 25.3 & 0.9 & 1.2 & 1.6 & 11.0 & 23.3 & 52.9 & 24.8 & 48.3 & 80.0 & 1.4 & 2.3 & 5.8 & 8.8 & 14.8 & 29.7 \\
\hline P-level & \multicolumn{3}{|c|}{0.1311} & \multicolumn{3}{|c|}{0.6742} & \multicolumn{3}{|c|}{0.3087} & \multicolumn{3}{|c|}{0.1734} & \multicolumn{3}{|c|}{0.5616} & \multicolumn{3}{|c|}{0.0755} & \multicolumn{3}{|c|}{0.3572} \\
\hline $\begin{array}{l}\mathrm{P}- \\
\text { adjusted }\end{array}$ & \multicolumn{3}{|c|}{0.4046} & \multicolumn{3}{|c|}{0.6742} & \multicolumn{3}{|c|}{0.500} & \multicolumn{3}{|c|}{0.4046} & \multicolumn{3}{|c|}{0.6552} & \multicolumn{3}{|c|}{0.4046} & \multirow{2}{*}{\multicolumn{3}{|c|}{0.500}} \\
\hline API (Eo) & & & & & & & & & & & & & & & & & & & & & \\
\hline absence & 14.8 & 18.1 & 26.0 & 9.2 & 15.4 & 25.4 & 0.9 & 1.2 & 1.6 & 14.8 & 27.3 & 62.3 & 26.6 & 51.9 & 76.4 & 1.3 & 2.1 & 3.5 & 7.5 & 12.5 & 20.2 \\
\hline presence & 15.0 & 21.2 & 39.6 & 5.2 & 14.3 & 24.9 & 0.8 & 1.0 & 1.4 & 9.2 & 25.6 & 55.0 & 27.9 & 49.8 & 77.3 & 1.4 & 3.0 & 7.4 & 10.0 & 17.9 & 24.6 \\
\hline P-level & \multicolumn{3}{|c|}{0.3836} & \multicolumn{3}{|c|}{0.5929} & \multicolumn{3}{|c|}{0.0476} & & 0.5585 & & & 0.992 & & & .2071 & & & 0.26 & \\
\hline $\begin{array}{l}\mathrm{P}- \\
\text { adjusted }\end{array}$ & & 0.6713 & & & 0.6917 & & & 0.3332 & & & 0.6917 & & & 0.992 & & & .6083 & & & 0.60 & \\
\hline $\begin{array}{l}\text { API } \\
\text { (wheez) }\end{array}$ & & & & & & & & & & & & & & & & & & & & & \\
\hline absence & 15.4 & 17.7 & 26.0 & 5.6 & 14.3 & 26.4 & 0.9 & 1.3 & 1.7 & 23.6 & 44.6 & 64.9 & 25.8 & 41.8 & 58.2 & 1.9 & 3.3 & 5.3 & 8.8 & 14.3 & 34.9 \\
\hline presence & 14.8 & 19.6 & 28.7 & 8.9 & 15.5 & 24.8 & 0.9 & 1.1 & 1.5 & 9.5 & 20.2 & 51.0 & 28.3 & 56.5 & 80.9 & 1.3 & 2.1 & 3.7 & 8.2 & 14.3 & 21.7 \\
\hline P-level & & 0.851 & & & 0.6268 & & & 0.3133 & & & 0.0158 & & & 0.2074 & & & 0.1045 & & & 0.73 & \\
\hline $\begin{array}{l}\mathrm{P}- \\
\text { adjusted }\end{array}$ & & 0.851 & & & 0.851 & & & 0.5482 & & & 0.1106 & & & 0.4839 & & & .3657 & & & 0.8 & \\
\hline $\begin{array}{l}\text { HDM } \\
\text { allergy }\end{array}$ & & & & & & & & & & & & & & & & & & & & & \\
\hline absence & 13.8 & 17.4 & 22.2 & 7.1 & 13.4 & 24.6 & 0.9 & 1.2 & 1.6 & 13.3 & 27.7 & 62.3 & 29.1 & 51.7 & 74.3 & 1.2 & 1.8 & 3.0 & 7.0 & 12.7 & 19.6 \\
\hline presence & 17.8 & 23.9 & 39.6 & 7.4 & 19.6 & 27.3 & 0.8 & 1.0 & 1.6 & 9.5 & 23.3 & 52.9 & 21.3 & 51.3 & 77.6 & 1.9 & 3.3 & 7.4 & 9.8 & 17.6 & 34.9 \\
\hline P-level & & 0.0061 & & & 0.1918 & & & 0.3759 & & & 0.6514 & & & 0.96 & & & 0.0232 & & & 0.05 & \\
\hline $\begin{array}{l}\mathrm{P}- \\
\text { adjusted }\end{array}$ & & 0.0427 & & & 0.3356 & & & 0.5262 & & & 0.7599 & & & 0.96 & & & .0812 & & & 0.13 & \\
\hline ANN & & & & & & & & & & & & & & & & & & & & & \\
\hline absence & 15.4 & 19.2 & 28.7 & 5.6 & 13.4 & 24.8 & 0.9 & 1.2 & 1.5 & 14.4 & 25.1 & 62.3 & 28.3 & 51.7 & 75.1 & 1.3 & 2.1 & 3.3 & 94 & 15.1 & 22.6 \\
\hline presence & 13.3 & 18.2 & 28.5 & 14.3 & 22.3 & 25.4 & 0.7 & 1.1 & 2.8 & 9.5 & 29.2 & 52.9 & 13.8 & 58.2 & 80.9 & 1.8 & 3.7 & 7.7 & 3.1 & 8.8 & 16.1 \\
\hline P-level & & 0.5829 & & & 0.0493 & & & 0.9901 & & & 0.897 & & & 0.9263 & & & $0.019 \varepsilon$ & & & 0.02 & \\
\hline $\begin{array}{l}\mathrm{P}- \\
\text { adjusted }\end{array}$ & & 0.9901 & & & 0.1150 & & & 0.9901 & & & 0.9901 & & & 0.9901 & & & .0752 & & & 0.07 & \\
\hline
\end{tabular}

\section{Figures}



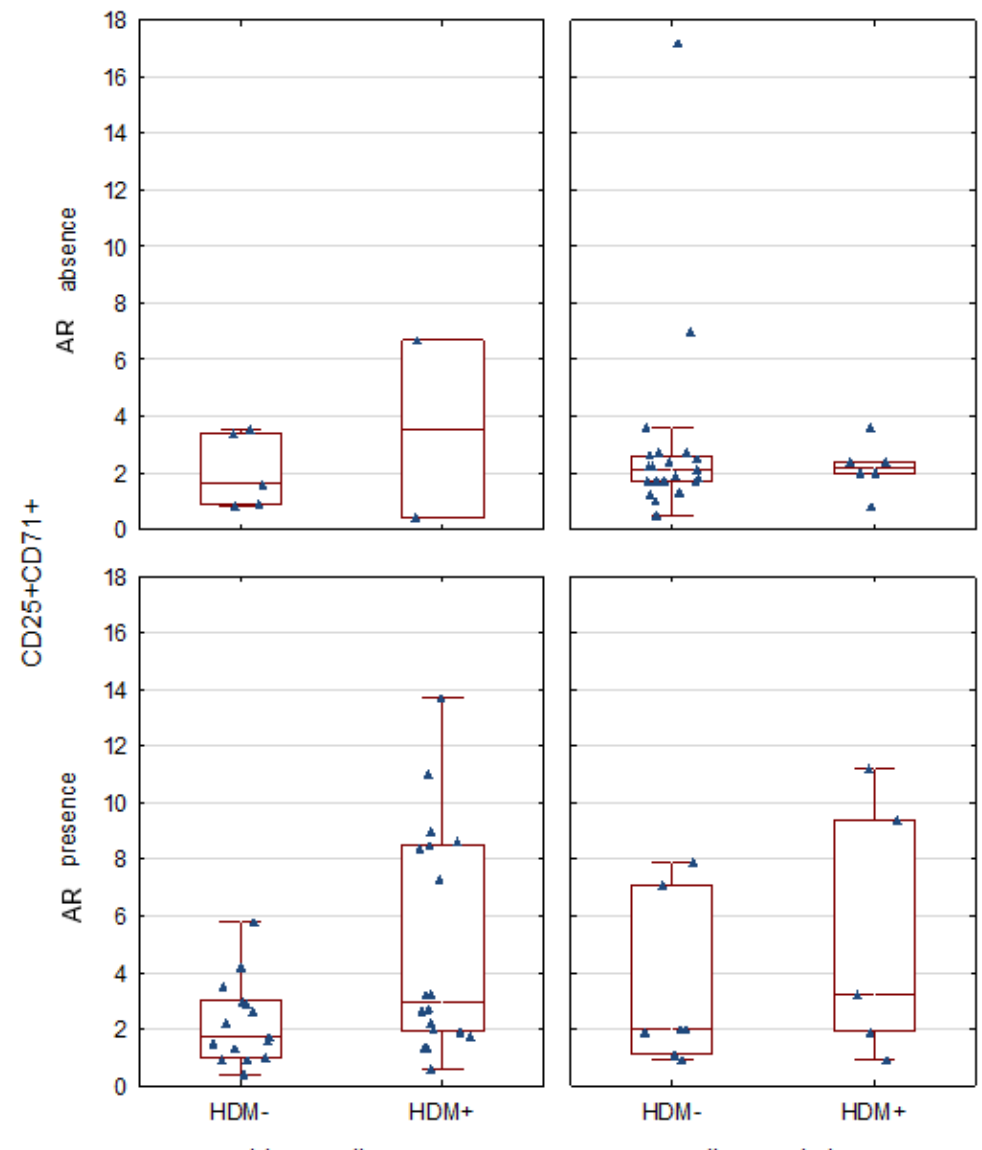

persistance asthma

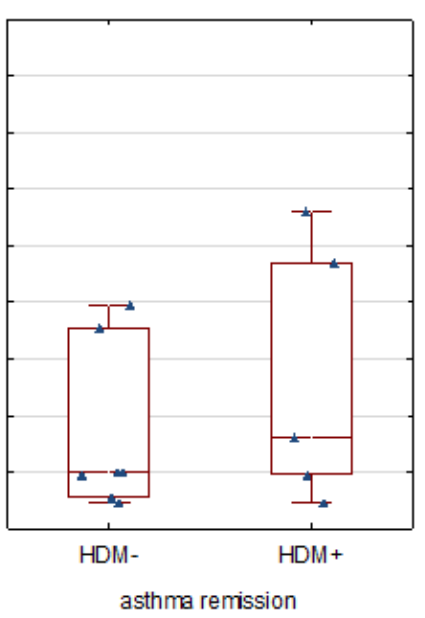

Figure 1

Allergy to house dust mite allergens (HDM) and the presence of allergic rhinitis (AR) symptoms determine the expression of CD25 + CD71 + cells in patients with/without asthma.

\section{Supplementary Files}

This is a list of supplementary files associated with this preprint. Click to download.

- Appendix.docx 